\section{DESCRIPTION OF A NEW SPECIES OF THE GENUS Litus Haliday (HyMENOPTERA: CHALCIDOIDEA: MYMARIDAE) FROM INDIA}

\author{
Tabassum Rehmat ${ }^{1}$ \& Shoeba Binte Anis ${ }^{2}$ \\ ${ }^{1,2}$ Department of Zoology, Aligarh Muslim University, Aligarh, \\ Uttar Pradesh 202002, India \\ ${ }^{1}$ tabassum.ento@gmail.com (corresponding author), \\ ${ }^{2}$ shoeba2007@rediffmail.com
}

The genus Litus Haliday, 1833 (Hymenoptera: Mymaridae) is represented by only 15 species across the world (Noyes 2015). Rehmat et al. (2009) recorded the genus from India and described two new species. The genus can be distinguished from other genera of the family by the robust and highly sclerotized head and mesosoma, and very long and narrow wings with long marginal fringe. In this paper, we describe a new species of the genus Litus from a female collected in Assam (India), and provide a key to the Indian species. The specimen is deposited in Insect Collections, Department of Zoology, Aligarh Muslim University, Aligarh, India (ZDAMU).

\section{Methods}

Absolute measurements in millimeters are given for body length only; all other measurements are relative, taken with the help of an ocular micrometer having a linear scale of 100 divisions, placed in the eye piece of a compound microscope. All the measurements were made at the same magnification for all the parts.
Litus assamensis sp. nov. (Image $1 \mathrm{~A}-\mathrm{G}$ )

urn:Isid:zoobank.org:act:65210813-D8E04CBB-8C2D-162007F8249F

Material examined: Holotype: HYM.CH.719, female (on slide under 4 coverslips); Kontola, Guwahati $\left(26.1833^{\circ} \mathrm{N} \& 91.7333^{\circ} \mathrm{E}\right)$, Assam, India, 28.x.2008, coll. F.R. Khan, ZDAMU.

Etymology: The species name is derived from the name of the state (Assam) from where the holotype was collected.

\section{Description}

Female: Body length, $0.35 \mathrm{~mm}$ (measured from slide mounted holotype).

Body colour (taken from slide mounted specimen) dark brown except distal last tergite of gaster and legs light brown. Antenna dark brown. Fore wing hyaline; hind wings subhyaline.

Head (Image 1A): Frontovertex broad, about $0.9 \times$ of head width; frons without a row of denticles; ocellar triangle with apical angle strongly obtuse; posterior ocelli nearly touching supraorbital trabecula; antennal torulus removed from transverse trabecula by a diatance equal to diameter of a torulus; frons with several minute tubercles; vertex with wide-meshed reticulations; temples strongly reticulate. Mandible unidentate, slightly longer than malar space (Image 1A). Antenna (Image 1B) with scape with longitudinal striations; pedicel longer than first funicle segment

DOI: http://dx.doi.org/10.11609/jott.1934.8.3.8615-8617 | ZooBank: urn:Isid:zoobank.org:pub:D14A60F2-03B7-4753-9C33-40C378B65DFD

Editor: Andreas Köhler, Universidade de Santa Cruz do, Brazil.

Date of publication: 26 March 2016 (online \& print)

Manuscript details: Ms \# 1934 | Received 01 April 2015 | Final received 29 February 2016 | Finally accepted 14 March 2016

Citation: Rehmat, T. \& S.B. Anis (2016). Description of a new species of the genus Litus Haliday (Hymenoptera: Chalcidoidea: Mymaridae) from India .Journal of Threatened Taxa 8(3): 8615-8617; http://dx.doi.org/10.11609/jott.1934.8.3.8615-8617

Copyright: @ Rehmat \& Anis 2016. Creative Commons Attribution 4.0 International License. JoTT allows unrestricted use of this article in any medium, reproduction and distribution by providing adequate credit to the authors and the source of publication.

Funding: University Grant Commission (UGC), New Delhi, India.

Conflict of Interest: The authors declare no competing interests

Acknowledgments: We thank Dr. M. Hayat, Principle Investigator of the 'Network Project on Insect Biosystematics' for valuable suggestions. We are also thankful to the ICAR, New Delhi and the National Coordinator of the project on Biosystematics for providing financial assistance. We thank the Chairman, Department of Zoology, Aligarh Muslim University, for providing research facilities. T. Rehmat gratefully acknowledges the University Grant Commission, New Delhi, for providing financial assistance. 


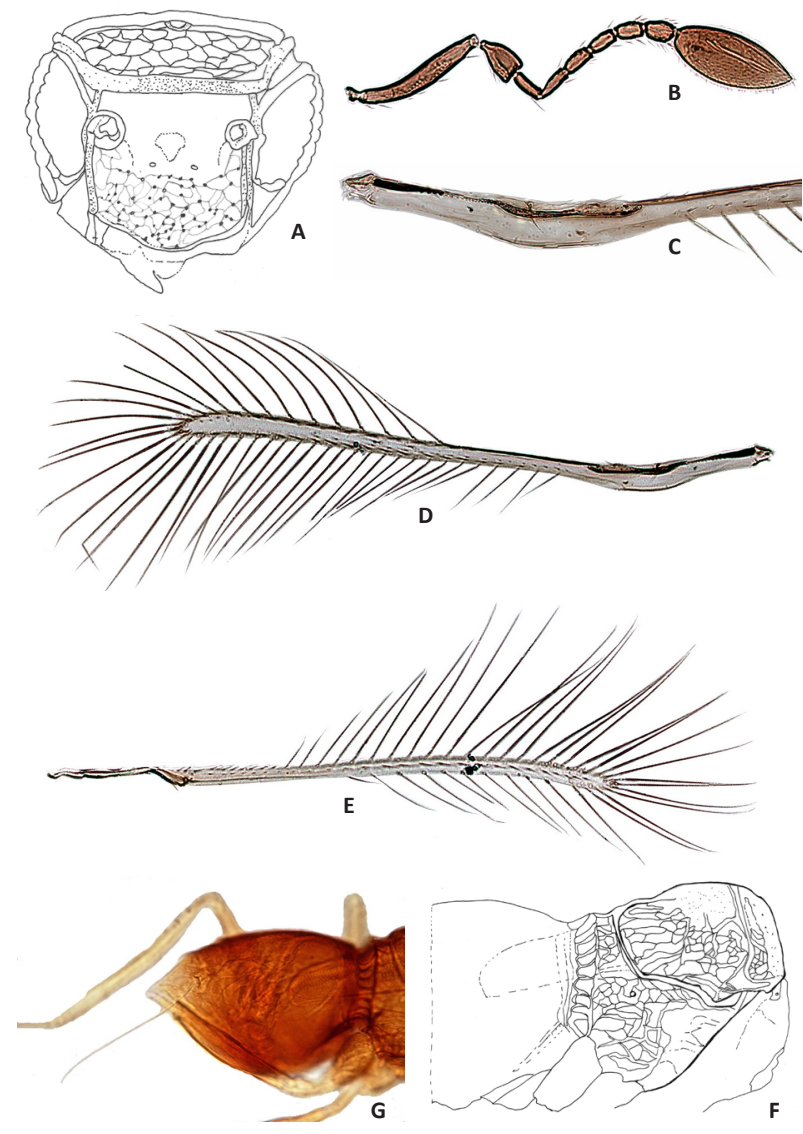

Image 1. Litus assamensis sp. nov. female (Holotype) (HYM.CH.719)

A - head; B - antenna; C - fore wing; D - fore wing basal part enlarged; E - hind wing; F - Mesosoma lateral; G - Metasoma, lateral.

(F1), covered with fine longitudinal striations; all funicle segments longer than broad; F1 and F3 equal in length; F2 longest; F4, F5 and F6 subequal in length; F6 slightly broader than preceding five funicle segments individually; clava about $2.4 \times$ as long as wide, much longer than preceding five funicle segments (F2-F6) combined, and with four longitudinal sensillae. Relative measurements of antennal segments; length (width): scape, 50(7); pedicel, 16(9); F1, 11(4); F2, 12(4); F3, 11(4); F4, 10(4); F5, 10(5); F6, 10(7); clava, 44(18).

Mesosoma (Image 1F) compact, strongly sculptured, except pronotum lightly sculptured and short; mesoscutum slightly longer than half of scutellum, with raised reticulate sculpture, and with $2+2$ setae, notular lines not clear; each axilla with one seta; scutellum with raised reticulations except anterior scutellum; propodeum with reticulation and with one seta on each side distal to spiracles. Fore wing (Image 1C,D) $26 \times$ as long as broad, disc almost bare except two setae present in the middle of the disc and a row of setae along anterior and posterior margin (about 18 setae). Hind wing (Image 1E) 33.3× as long as broad, disc with a line of setae. Legs with sclerotized coxae.

Metasoma (Image 1G) longer than mesosoma (75:55); first tergite of gaster (= TI) long and covering three-fifths of gaster length; last tergite (= TVII) conical; ovipositor (Image 1F) short, as long as length of mid tibia; $0.7 \times$ of hind tibia length; about $0.6 \times$ of gaster length and not exserted.

Male: Unknown.

Hosts: Unknown.

Distribution: India: Assam.

Comments: This new species appears to be very similar to Litus sutil Triapitsyn \& Berezovskiy (2004), but differs in the following characters: antennal pedicel with longitudinal striations, clava $2.5 \times$ as long as wide; fore wing $26 \times$ as long as broad; ovipositor $0.6 \times$ of gaster length (In L. sutil: pedicel without longitudinal striations, clava $3.5 \times$ as long as broad; fore wing $21 \times$ as long as broad; ovipositor $2.07 \times$ of gaster length). The new species also differs from other two Indian species by the characters given in the key.

\section{References}

Haliday, A.H. (1833). An easy on the classification of the parasitic Hymenoptera of Britain, which corresponds with the Ichneumons minuti of Linnaeus. Entomological Magazine 1: 259-276, 333-350.

\section{Key to Indian species of Litus (Females)}

1. Anterior margin of frons with denticles (Rehmat \& Anis 2009; Image 3); clava length subequal or slightly shorter thanfive preceding funicle segments combined (Rehmat \& Anis 2009; Images 1A,F) ................................... 2 Anterior margin of frons without denticles (Image 1A); clava length longer than five preceding funicle segments combined (Image 1B)..... L. assamensis sp. nov.

2. Ovipositor originates from near base of gaster, and strongly exserted at apex (Rehmat et al. 2009; Image 11), exserted part $0.39 x$ of gaster length; ovipositor $1.98 \times$ as long as mid tibia and $1.48 x$ as long as hind tibia L. triapitsyni Rehmat \& Hayat Ovipositor originates from basal fourth of gaster and very slightly exserted (Rehmat et al. 2009; Image 1F), the exserted part about $0.17 \times$ of gaster length; ovipositor $1.65 \times$ as long as mid tibia and $1.30 \times$ as long as hind tibia 
Noyes, J.S. (2015). Universal Chalcidoidea Database, World Wide Web electronic publication. Available from http://www.nhm.ac.uk/ entomology/chalcidoids/ index.html (accessed on 15 March 2015).

Rehmat, T., S.B. Anis \& M. Hayat (2009). Record of the Genus Litus Haliday (Hymenoptera: Chalcidoidea: Mymaridae) from India, with description of two species. Journal of Threatened Taxa 1(7): 370374; http://dx.doi.org/10.11609/JoTT.o2199.370-4

Triapitsyn, S.V. \& V.V. Berezovskiy (2004). Review of the genus Litus Haliday, 1833 in the Holarctic and Oriental regions, with notes on the Palaearctic species of Arescon Walker, 1846 (Hymenoptera: Mymaridae). Far Eastern Entomologist 141: 1-24. 